\title{
Degradation of concentrating solar thermal reflectors in acid rain atmospheres
}

\author{
A. García-Segura, ${ }^{\text {a, }}$, A. Fernández-García ${ }^{\mathrm{a}}$, M.J. Ariza ${ }^{\mathrm{b}}$, F. Sutter ${ }^{\mathrm{c}}$, L. Valenzuela ${ }^{\mathrm{a}}$ \\ ${ }^{a}$ CIEMAT, Plataforma Solar de Almería, Ctra. Senés, km 4, P.O. Box 22, 04200 Tabernas, Almería, Spain \\ ${ }^{\mathrm{b}}$ Universidad de Almería, Física Aplicada, CITE II-A, 04120, Almería, Spain \\ ${ }^{\text {c } D L R, ~ G e r m a n ~ A e r o s p a c e ~ C e n t e r, ~ I n s t i t u t e ~ o f ~ S o l a r ~ R e s e a r c h, ~ P l a t a f o r m a ~ S o l a r ~ d e ~ A l m e r i ́ a, ~ C t r a . ~ S e n e ́ s, ~ k m ~ 4, ~ P . O . ~ B o x ~ 39, ~} 04200$ \\ Tabernas, Almería, Spain
}

\begin{abstract}
Given the importance that concentrating solar power technologies have had in recent years, the interaction between humid atmospheres in which $\mathrm{SO}_{2}$ is the main pollutant and the metal reflecting layers of the solar concentrators is a major concern that should be addressed. Previous durability studies have urged the importance of designing an accelerated aging test protocol for simulating aggressive industrial atmospheres that solar reflector materials are bound to encounter. Therefore, three types of reflectors were tested in an acid-rain (or Kesternich) chamber at various temperatures and gas concentrations based on the DIN 50018 and ISO 6988 standards. The results showed the significant effect of high $\mathrm{SO}_{2}$ concentrations rather than high temperatures on silvered-glass reflectors, although synergy should not be disregarded. Strong reductions in specular reflectance were found for one type of silvered reflector compared to another type, highlighting the significance of material processing and its effects on their final performance. Aluminum reflectors were not damaged as much as silvered-glass reflectors, but under microscopic inspection, a wide range of noticeable corrosion defects could be found in all the materials. Comparisons between the most representative Kesternich test and samples from an outdoor industrial site permitted realistic lifetime correlations for commercial silvered-glass reflectors.
\end{abstract}

Keywords: concentrating solar technology; solar reflector; accelerated aging test; acid rain; service lifetime prediction.

\section{Nomenclature}

Acronyms

CSP Concentrating solar power

PVD Physical vapor deposition

CASS Copper-accelerated acetic acid salt spray

\footnotetext{
* Corresponding author. Tel.: +34950 387 800; Fax: +34950 365 015. E-mail addresses: agarcia@psa.es (A. García-Segura), afernandez@psa.es (A. Fernández-García),mjariza@ual.es (M.J. Ariza), florian.sutter@dlr.de (F. Sutter), loreto.valenzuela@psa.es (L. Valenzuela).
} 
DIN

ISO

PTC

ASTM

SLR

\section{Symbols}

$T$

RH

V

$\rho_{\lambda, \varphi}\left(660 \mathrm{~nm}, 15^{\circ}, 12.5 \mathrm{mrad}\right)$

$\rho_{s, h}\left([280,2500] \mathrm{nm}, 8^{\circ}, h\right)$

$N$

W

$\left[\mathrm{SO}_{2}\right]$
Deutsches Institut für Normung (German Institute for Standardization)

International Organization for Standardization

parabolic-trough collector

American Society for Testing and Materials

Single-lens reflex

Temperature, ${ }^{\circ} \mathrm{C}$

Relative humidity, \%

Volume, $\mathrm{dm}^{3}$

Monochromatic specular reflectance at wavelength $\lambda=660 \mathrm{~nm}$, incidence angle $\theta_{i}=15^{\circ}$ and acceptance half-angle $\varphi=12.5 \mathrm{mrad}$,

Solar-weighted hemispherical reflectance in the wavelength range of $\lambda=[280,2500] \mathrm{nm}$ and at incidence angle $\theta_{i}=8^{\circ}$, -

Number of corrosion spots, -

Scratch width, $\mu \mathrm{m}$

Sulfur dioxide concentration, ppm

\section{Introduction}

Concentrating solar thermal technologies (known as CSP, concentrating solar power) have undergone spectacular development in the last few decades [1]. While in 2006 CSP installed capacity was $0.5 \mathrm{GW}_{\mathrm{e}}$ worldwide, it has increased by a factor of 10 to over $5 \mathrm{GW}_{\mathrm{e}}$ today. It is estimated that CSP technologies will provide about $11 \%$ of total electricity production by 2050 [2], as a result of the huge effort made by numerous countries in the last few years in introducing noteworthy renewable-energy programs [3,4]. CSP plants may be located near industrial areas because of the availability of highly qualified personnel and infrastructures already in place there. In addition, industry is showing growing interest in the use of CSP technologies as the source of electricity, steam and process heat. However, these areas may face significant concentrations of sulfur dioxide $\left(\mathrm{SO}_{2}\right)$, which is the gas mainly responsible for atmospheric acidification [5]. This phenomenon, which has been of great concern in the last several years, has resulted in numerous studies [6-8]. Combustion of fossil fuels containing sulfur and smelting metal sulfide ores are the main sources of manmade emissions of $\mathrm{SO}_{2}$ [9]. Although recent studies have reported a dramatic decrease in atmospheric $\mathrm{SO}_{2}$ levels in several European cities, mainly due to the use of cleaner fuels and higher-efficiency engines [10], this airborne pollutant (alone or in combination with other corrosive gases and salinity) can cause 
serious degradation of metals [11] and in this case, of the metal CSP absorber and reflector parts used in CSP and solar thermal collector applications [12].

Of the current types of CSP reflectors, silvered-glass and aluminum reflectors are the most widely deployed, and both contain metals prone to corrosion, thus negatively affecting their optical performance. Silvered-glass reflectors are based on a thin silver reflective layer which is protected by a 1-4 mm glass substrate on the front and usually a copper layer and several protective coats of paint on the back. Due to their high performance and durability, they have been regarded as the most reliable technology to date [13]. On the other hand, aluminum reflectors consist of a physical vapor deposited (PVD) aluminum layer, on an aluminum substrate protected by transparent $\mathrm{SiO}_{2}$ sol-gel coatings. They are frequently used in small-scale concentrators for process heat applications where atmospheres are likely to be polluted [14].

The importance of the interaction between gases in ambient air and the silver used in solar concentrator reflectors was identified by Schissel and Czanderna in 1980 [15]. As reported in previous studies $[16,17]$, humid atmospheres in which $\mathrm{SO}_{2}$ is the main corrosion agent are aggressive and harmful to many metals (silver, copper, etc.), which are also present in the reflective layer of solar reflectors, thus compromising their optimal performance. More recent studies have carried out extensive laboratory and outdoor exposure testing of solar reflector materials. The most appropriate accelerated aging test that reproduced similar degradation to outdoor defects in silvered-glass reflectors was reported to be the copper accelerated salt spray (CASS) test $[18,19]$. Nevertheless, an additional accelerated aging test campaign simulating aggressive industrial environments was considered necessary. A wide variety of accelerated aging experiments have been applied to aluminum reflectors and some correlations with representative outdoor sites derived [20]. One type of corrosion mechanism reproduced with the CASS test and acceleration factors for three different types of reference sites have been assigned accordingly. However, this is only a first step in lifetime prediction of solar reflector materials. To date, few solar reflector durability studies have succeeded in providing realistic lifetime estimates [21], and only a few of them have been devoted to the effect of humid sulfurcontaining atmospheres $[5,22,23]$. It is therefore considered a major issue that must be addressed and studied carefully. Special attention should be given the Kesternich test [24, 25], which uses high concentrations of $\mathrm{SO}_{2}$ in water-saturated atmospheres and has been used before to simulate the degradation of materials normally subjected to atmospheric $\mathrm{SO}_{2}$. This standardized aging experiment has been used, for example, to study the degradation and corrosion of historical stained glass windows [26], Zn protective coatings used in medical equipment [27] and the suitability and durability of an anti-graffiti product for porous materials in monuments and historic buildings [28]. Nevertheless, there are various procedures for studying the many types of solar reflector degradation, mainly focused on the effects of erosion [29] and corrosion [30].

In view of the significant corrosion of the metals in solar reflectors by atmospheric $\mathrm{SO}_{2}$, the aims of this study were to:

- Examine the behavior of three different types of conventional solar reflectors subjected to a number of accelerated aging tests based on the current Kesternich test methods. Several scenarios were explored, including different temperatures and corrosive gas concentrations at $100 \%$ relative humidity.

- Select the most suitable accelerated-aging conditions for solar reflector applications and the best reflector material for high-humidity $\mathrm{SO}_{2}$-containing atmospheres. 
- Compare accelerated aging results with exposure to outdoor industrial environments of industrial interest and establish preliminary correlations between them.

To approach these objectives, three reflector materials were weathered in eight different corrosion tests with a wide range of ambient conditions and several evaluation methods were used to assess their performance. Finally, the acceleration factor in one of the aging experiments was calculated by comparing it to one real outdoor exposure.

\section{Material and methods}

This section includes a description of the reflector materials studied, the aging tests carried out and the evaluation techniques used to characterize their degradation.

\subsection{Reflector materials}

Three candidate commercial solar reflectors were selected for the corrosion experiments, two second-surface silvered-glass reflectors (Types 1 and 2) and a first-surface aluminum reflector (Type 3), as described in [31]. Fig. 1 shows a $10 \times 10 \mathrm{~cm}^{2}$ sample of each glass reflector and a $12 \times 12 \mathrm{~cm}^{2}$ sample of the aluminum reflectors. Three replicates were used to ensure representative results of corrosion tests. Type 1 silvered-glass reflector samples were cut from larger commercial parabolic-trough collector (PTC) mirror facets having unprotected edges. The samples were also scratched so that all the protective and reflective layers were penetrated, exposing the metal directly to the corrosive atmosphere. The scratch has already been used in the literature [31] to represent damage that reflectors may already have undergone at a real site due to aggressive external conditions, such as sandstorms [32], careless handling, cleaning procedures [33], etc.

As seen in Fig. 1left, Type 1 silvered-glass samples are the most unfavorable case of silver exposed to the corrosive environment, because all three have unprotected cut edges and a $2-\mathrm{cm}$ long scratch in the paint on the back. In contrast, the silver in Type 2 silvered-glass reflectors (Fig. 1center) is less exposed, since they were specifically manufactured to a $10 \times 10 \mathrm{~cm}^{2}$ format specification with four original, protected edges and no deliberate damage. Therefore, Type 1 reflectors are referred to as predamaged silvered-glass reflectors and Type 2 as undamaged silvered-glass reflectors. Both Type 1 and Type 2 samples were produced by the same commercial silvered-glass reflector manufacturer. Edges are not protected in aluminum reflectors for real applications, and so first-surface aluminum reflectors (Fig. 1right) include both unprotected edges and a $2-\mathrm{cm}$ scratch on the front, to expose the reflective layer to the corrosive atmosphere. The main features of the reflector materials studied are summarized in Table 1. 

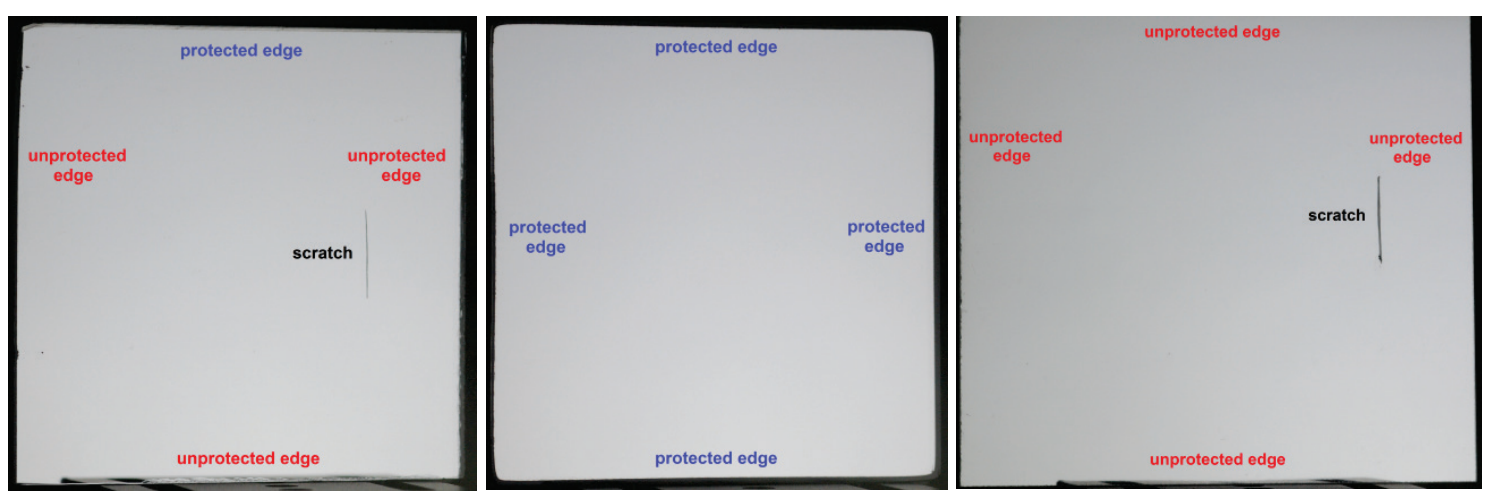

Fig. 1. Solar reflector samples weathered in the corrosion experiments: Type 1, predamaged silvered-glass reflector (left), Type 2, undamaged silvered-glass reflector (center), and Type 3, predamaged aluminum reflector (right). The protected edges are marked in blue, unprotected edges in red and the scratch in black.

Table 1. Main characteristics of solar reflector materials.

\begin{tabular}{|c|c|c|c|}
\hline Features & Type 1 silvered-glass & Type 2 silvered-glass & Aluminum \\
\hline Type of reflector & Second surface & Second surface & First surface \\
\hline Main use & Heliostats/PTC & Heliostats/PTC & Small concentrators \\
\hline Size $\left(\mathrm{cm}^{2}\right)$ & $10 \mathrm{x} 10$ & $10 \mathrm{x} 10$ & $12 \times 12$ \\
\hline Material layers & $\begin{array}{c}\text { Low iron } \\
\text { glass/Ag/Cu/Paint } \\
\text { coatings }\end{array}$ & $\begin{array}{c}\text { Low iron } \\
\text { glass/Ag/Cu/Paint } \\
\text { coatings }\end{array}$ & $\begin{array}{c}\text { Nano-composite/PVD } \\
\text { layer } \\
\text { system/Anodizing } \\
\text { layer/Al substrate }\end{array}$ \\
\hline $\begin{array}{c}\text { Typical initial } \\
\rho_{\lambda, \varphi}\left(660 n m, 15^{\circ}, 12.5 m\right. \\
\text { rad })\end{array}$ & $0.950 \pm 0.001$ & $0.959 \pm 0.001$ & $0.828 \pm 0.001$ \\
\hline $\begin{array}{c}\text { Type of edge } \\
\text { protection }\end{array}$ & $\begin{array}{c}1 \text { original edge }+3 \\
\text { fractured edges }\end{array}$ & 4 protected edges & 4 unprotected edges \\
\hline Scratch & Yes & No & Yes \\
\hline
\end{tabular}

\subsection{Weathering experiments}

An HK 300 M weathering chamber, also known as a Kesternich cabinet (Fig. 2left), was used for the corrosion experiments (Kesternich tests) following the ISO 6988 and DIN 50018 standards $[24,25]$. The test temperature, $T$, may be varied from $+5{ }^{\circ} \mathrm{C}$ to $+50{ }^{\circ} \mathrm{C}$ and the $\mathrm{SO}_{2}$ doses from 0.1 to $6.0 \mathrm{dm}^{3}$ (333.3-20000 ppm). Three Kesternich tests at 0.2, 1.0 and $2.0 \mathrm{dm}^{3}$ of $\mathrm{SO}_{2}$ in a $300 \mathrm{dm}^{3}$ chamber interior were performed as proposed in the aforementioned standards. The tests consist of 24-hour cycles divided into two phases. The first one is the heating-corrosive phase, in which the samples are exposed for $8 \mathrm{~h}$ to condensed humidity $(R H=100 \%)$ at $40{ }^{\circ} \mathrm{C}$ and the targeted $\mathrm{SO}_{2}$ concentration. In the second phase, for the following $16 \mathrm{~h}$, the samples are subjected to ambient conditions, i.e. no gas, room temperature $\left(18-28{ }^{\circ} \mathrm{C}\right)$ and $R H=75 \%$ maximum. To study the influence of temperature, two additional tests were carried out at 25 and $50{ }^{\circ} \mathrm{C}$ and the $\mathrm{SO}_{2}$ dose set at $1.0 \mathrm{dm}^{3}$. This volume was considered the most appropriate of the three, because degradation was more significant than at the low concentration, but not as extreme as at the high concentration (see section 3). Finally, the same cyclic weathering experiments were reproduced without gas at the same $R H$ and $T(25,40$ and 
$50{ }^{\circ} \mathrm{C}$ ) using a standard climatic chamber (Fig. 2right) in order to study the difference between degradation with and without $\mathrm{SO}_{2}$.

To summarize, the experimental conditions of the eight weathering tests performed in this study are presented in detail in Table 2. The $\mathrm{SO}_{2}$ volume (in $\mathrm{dm}^{3}$ ) and temperature (in ${ }^{\circ} \mathrm{C}$ ) are given in the test name to distinguish between the different experimental conditions, e.g., K_1_40 stands for the Kesternich test at $V_{\mathrm{SO} 2}=1 \mathrm{dm}^{3}$ and $T=40^{\circ} \mathrm{C}$. All the tests consisted of a total of 20 cycles, and samples were analyzed before the tests and after 1,2, 5, 10, 15, and 20 cycles, as recommended by the DIN 50018 standard. Samples were placed inside the chambers on a tray made of an inert material at a $45^{\circ}$ tilt angle. They were gently rinsed with deionized water before optical analysis.

Table 2. Corrosion test conditions.

\begin{tabular}{|c|c|c|c|c|}
\hline Name of test & $\left.\boldsymbol{V}_{\mathbf{S O 2}} \mathbf{( d m}^{\mathbf{3}}\right)$ & {$\left[\mathbf{S O}_{2}\right] \mathbf{( p p m )}$} & $\left.\boldsymbol{T} \mathbf{}^{\circ} \mathbf{C}\right)$ & $\boldsymbol{R H} \mathbf{( \% )}$ \\
\hline K_0_25 & 0.0 & 0.0 & 25 & 100 \\
\hline K_0_40 & 0.0 & 0.0 & 40 & 100 \\
\hline K_0_50 & 0.0 & 0.0 & 50 & 100 \\
\hline K_0.2_40 & 0.2 & 666.7 & 40 & 100 \\
\hline K_1_25 & 1.0 & 3333.3 & 25 & 100 \\
\hline K_1_40 & 1.0 & 3333.3 & 40 & 100 \\
\hline K_1_50 & 1.0 & 3333.3 & 50 & 100 \\
\hline K_2_40 & 2.0 & 6666.7 & 40 & 100 \\
\hline
\end{tabular}

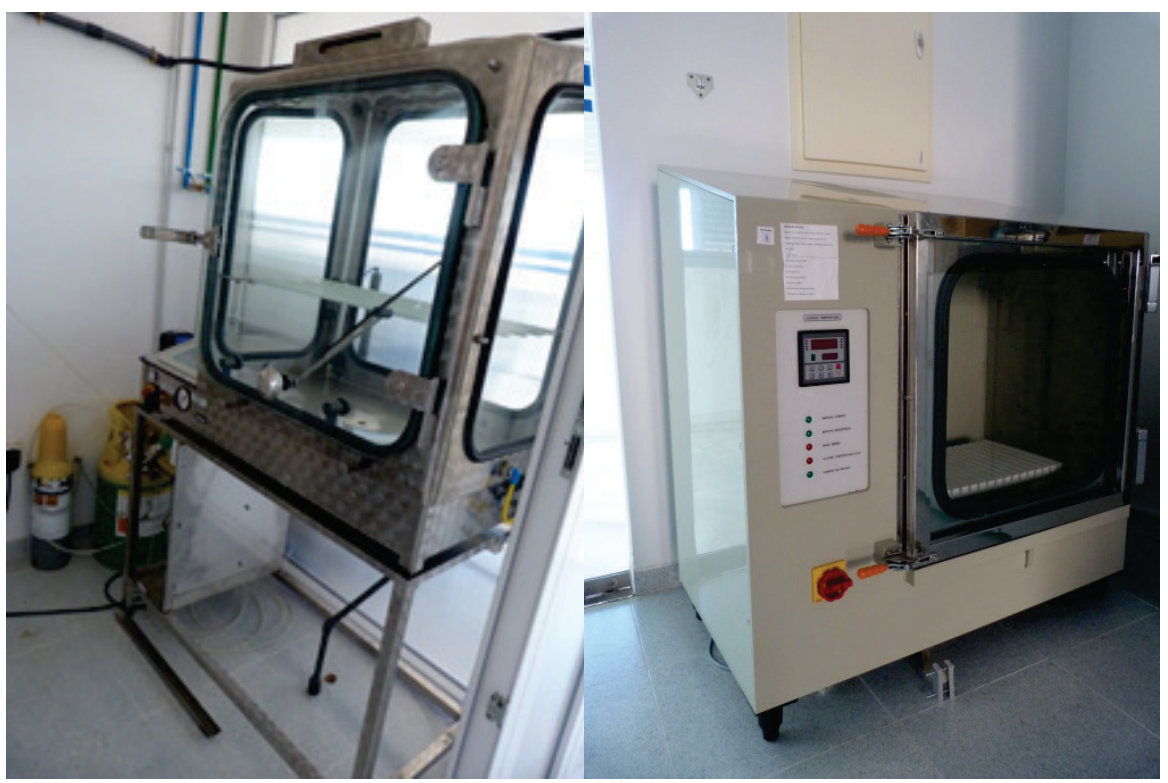

Fig. 2. Kesternich test chamber HK 300 M KÖHLER Automobiltechnik GmbH (left) and Vötsch condensed water test chamber (right). 


\subsection{Reflector assessment}

Monochromatic specular reflectance, $\rho_{\lambda, \varphi}\left(660 \mathrm{~nm}, 15^{\circ}, 12.5 \mathrm{mrad}\right)$, was monitored at a $15^{\circ}$ incidence angle in a wavelength range of 635 to $685 \mathrm{~nm}$ with a peak at $660 \mathrm{~nm}$, and $12.5 \mathrm{mrad}$ acceptance angle with a portable Devices and Services 15R-USB reflectometer [34]. Nine different areas were measured in every reflector sample, with three repetitions in the area of the scratch, for statistically representative results as described in the literature [31].

Spectral hemispherical reflectance, $\rho_{s, h}\left([280,2500] \mathrm{nm}, 8^{\circ}, h\right)$, was determined from 280 to $2500 \mathrm{~nm}$ at an $8^{\circ}$ angle of incidence using a Perkin Elmer Lambda 1050 spectrophotometer with a $150 \mathrm{~mm}$ diameter integrating sphere accessory [35]. Solar-weighted hemispherical reflectance was calculated following ISO Standard 9050 [36] and the direct solar radiation spectrum from ASTM G173-03 [37]. Due to equipment restraints, hemispherical reflectance was only measured at the reflector center, but every sample was measured three times, rotating $90^{\circ}$ each time to check for any possible anisotropy.

As previously demonstrated [31], reflectance does not always give enough information to thoroughly assess the performance of solar reflectors. Therefore, several different microscopic and analytical techniques were used to characterize the corrosion defects of greatest interest. Visual characterization was performed with a Panasonic LUMIX model DMC-F745 digital camera. Microscopic defects on the reflective layer and painted side of the silvered-glass reflectors and on the reflective surface of the aluminum reflectors were inspected by optical microscopy using a Zeiss Axio CSM 700 3D light confocal microscope [38], which can work in both 2D optical and 3D confocal modes. Damage was also measured with this microscope, taking into account that the maximum dimension of corrosion spots is their characteristic length. The reflector surface was also evaluated with an in-house device which takes single-lens reflex (SLR) images of the specimens in a dark chamber, and then the corrosion spots and total corroded area were assessed using a MATLAB routine. Means of total corroded areas were given for every three replicates tested per reflector type.

\section{Results and discussion}

This section presents and discusses the most significant results of the three reflector types studied. It also compares the results of one of the accelerated tests to corrosion data from one exposed near a real industrial site and a correlation is made.

\subsection{Predamaged silvered-glass reflectors (Type 1)}

Reflectance is the best parameter for quantifying the optical quality of solar reflectors [39]. Consequently, both monochromatic specular and hemispherical reflectance were monitored during the tests. The results of the reflective area undamaged at the start of the experiment (i.e. all of the reflector surface except the area of the scratch [31]) are shown in Fig. 3. No significant changes were observed in the specular reflectance measured. Although a loss of $-0.002 \pm 0.002$ was found at the end of the tests at the highest temperature (K_0_50 and K_1_50, shown in Fig. 3left), it is considered negligible, because it is within the measurement uncertainty of the equipment. Results were similar for the decrease in solar-weighted hemispherical reflectance, as displayed in Fig. 3right. 


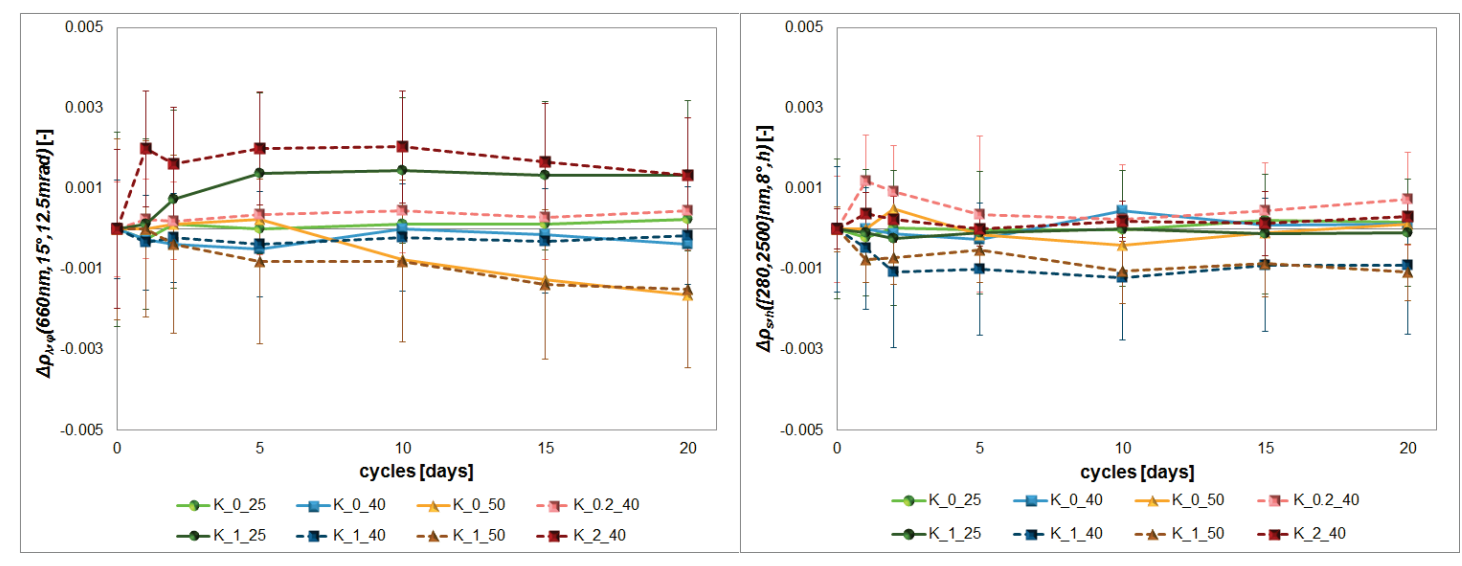

Fig. 3. Changes in mean increment in monochromatic specular reflectance during cycles (left) and in solar-weighted hemispherical reflectance (right) in the undamaged areas of Type 1 silvered-glass reflectors in weathering tests.

The reflectance results show that reflector surfaces were apparently not degraded by the Kesternich tests. But as already reported in previous studies [31], it is very important to analyze the optical performance of reflectors further with other tools. The samples were therefore also examined by optical microscopy on both the reflective surface and painted back to track the appearance and development of any defects. Table 3 summarizes the most significant corrosion defects found on the reflective layer of Type 1 silvered-glass reflectors at the end of testing (20 cycles). According to these microscopic results, the damage done in the $\mathrm{SO}_{2}$-free tests was negligible, while the tests with the gas may be classified by severity as low (K_0.2_40), medium (K_1_25, K_1_40) and high (K_1_50, K_2_40) as follows.

K_ $0.2 \_40$ is considered to be a low severity test because it produced only a few (6) small spots on the reflector surface, no corrosion of the original (protected) sample edges, and cut (unprotected) edges were only moderately affected. In addition, corrosion of the total reflector area (Total Corr. in Table 3) was $(1.8 \pm 0.5) \%$. Both K_1_25 and K_1_40 are classified as medium, with a total corrosion area of $(2.6 \pm 0.4) \%$ and $(3.7 \pm 1.1) \%$, respectively. However, there are some differences between them. Whereas K_1_40 caused more corrosion near the edges than K_1_25 (218 and $82 \mu \mathrm{m}$ larger on cut and original edges, respectively), corrosion spots were larger in the latter (the largest spot found was $109 \mu \mathrm{m}$ larger in K_1_25).

Tests K_1_50 and K_2_40 were responsible for the worst reflector degradation, (5.6 \pm 1.0$) \%$ and $(11.5 \pm 1.6) \%$ of the total corroded area, respectively. Numerous large spots also appeared under the extreme conditions (up to 95 spots with a maximum characteristic length over $1100 \mu \mathrm{m}$ ), as well as significant corrosion penetration near the edges, which is even visible to the naked eye after Test K_2_40 (up to centimeters long). Therefore, Test K_2_40 is more aggressive than $\mathrm{K} \_1$ 150, suggesting that higher gas concentration is more harmful than higher $T$, although synergy of both parameters should also be considered.

Although the tests with no gas (K_0_25, K_0_40 and K_0_50) did not cause any significant degradation on the reflective layer of Type 1 reflector materials, these humidity tests do promote occasional blistering of the paint on the back, as shown in Fig. 4. Such blisters might not be easy to detect in the gas tests because they are prone to flaking off and leaving pinholes as a result of the high severity of the Kesternich tests [40]. Even though not all corrosion spots 
may have a corresponding pinhole in the paint, the presence of such a pinhole probably promotes the formation of a corrosion spot. Table 4 shows examples of correspondence between corrosion spots on the reflective layer and pinholes found on the back coating of reflector materials after aging with Kesternich tests.

\section{Table 3}

Summary of corrosion found on the reflective area of Type 1 silvered-glass reflectors after 20 cycles of all weathering tests. Total $N$ : sum of the number of corrosion spots visible to the naked eye at the end of testing on a $300-\mathrm{cm}^{2}$ total reflector surface, Size: characteristic length of the largest spot $(\mu \mathrm{m})$, Max. Pen.: maximum penetration of corrosion near the edge $(\mu \mathrm{m}), \Delta \rho_{\lambda, \varphi}$ : mean increment in monochromatic specular reflectance on reflector surfaces not predamaged (), Total Corr.: mean total corrosion of the whole reflector surface (\%). Microscope images are 10x.

\begin{tabular}{|c|c|c|c|c|c|c|c|c|c|}
\hline \multirow{2}{*}{\multicolumn{2}{|c|}{ Corrosion features }} & \multicolumn{8}{|c|}{ Reflective area of Type 1 silvered-glass reflectors } \\
\hline & & K_0_25 & K_0_40 & K_0 50 & K_0.2_40 & K_1_25 & K_1_40 & K_1 50 & K_2 40 \\
\hline \multirow{3}{*}{$\frac{n}{\circ}$} & $\begin{array}{c}\text { Microscope } \\
\text { image }\end{array}$ & - & - & -- & a & & 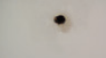 & & \\
\hline & Total $N$ & 0 & 0 & 0 & 6 & 8 & 8 & 12 & 95 \\
\hline & Size (um) & -- & -- & -- & 264 & 706 & 597 & 1167 & 1188 \\
\hline \multirow{2}{*}{ 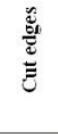 } & $\begin{array}{l}\text { Microscope } \\
\text { image }\end{array}$ & & & & & & & & \\
\hline & $\begin{array}{c}\text { Max. Pen. } \\
\text { (iㅡ) }\end{array}$ & No corrosion & No corrosion & No corrosion & 793 & 1095 & 1313 & 3981 & $\mathrm{~cm}$ order \\
\hline \multirow{2}{*}{ 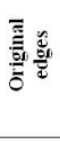 } & $\begin{array}{c}\text { Microscope } \\
\text { image }\end{array}$ & & & & & & & & \\
\hline & $\begin{array}{l}\text { Max. Pen. } \\
\text { (uim) }\end{array}$ & No corrosion & No corrosion & No corrosion & No corrosion & 999 & 1081 & 3817 & 8959 \\
\hline \multirow{3}{*}{ 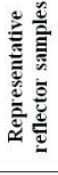 } & $\begin{array}{c}\text { Photo } \\
\text { (10x10) } \mathrm{cm}^{2} \\
\text { sample }\end{array}$ & & & & & & & & \\
\hline & 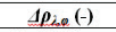 & $0.000 \pm 0.000$ & $0.000 \pm 0.000$ & $-0.002 \pm 0.000$ & $0.000 \pm 0.001$ & $0.001 \pm 0.002$ & $0.000 \pm 0.001$ & $-0.002 \pm 0.002$ & $0.001 \pm 0.001$ \\
\hline & $\begin{array}{c}\text { Total Corr. } \\
(\%)\end{array}$ & $0.0 \pm 0.0$ & $0.0 \pm 0.0$ & $0.0 \pm 0.0$ & $1.8 \pm 0.5$ & $2.6 \pm 0.4$ & $3.7 \pm 1.1$ & $5.6 \pm 1.0$ & $11.5 \pm 1.6$ \\
\hline
\end{tabular}
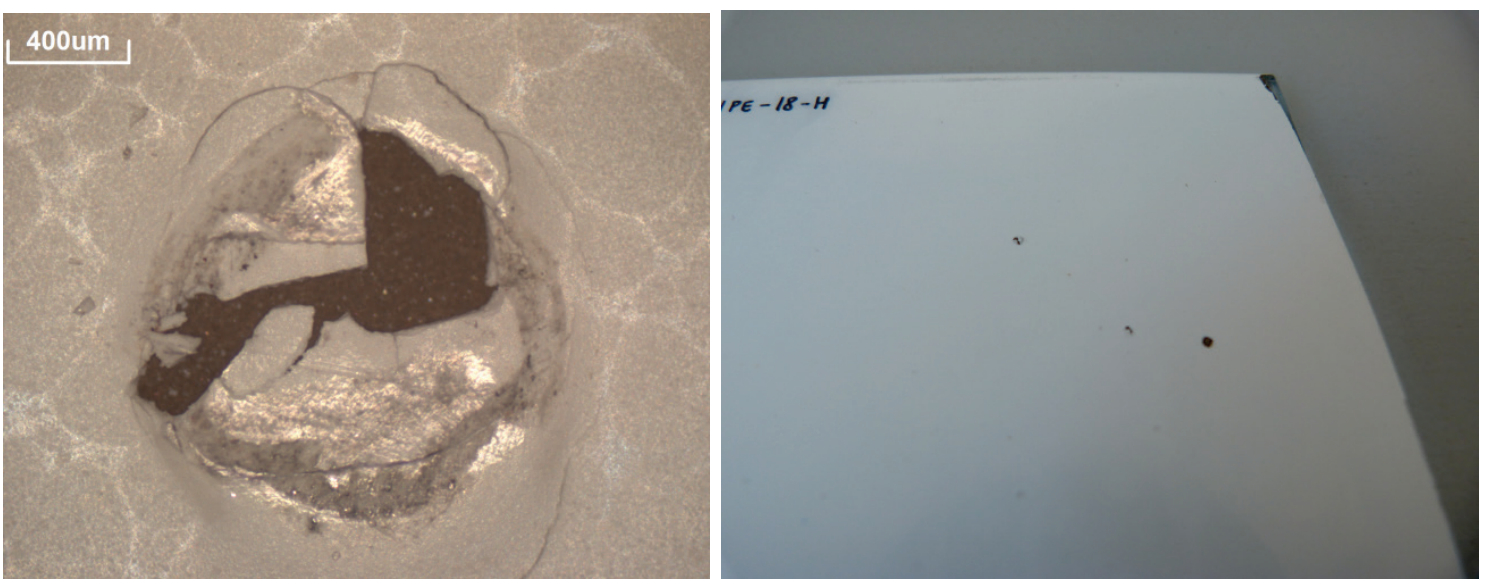

Fig. 4. Microscope image of a paint blister on the back of a Type 1 silvered-glass reflector sample taken at $5 \mathrm{x}$ magnification after 20 cycles of the K_0_40 humidity test (left), unmagnified image of blisters (right). 


\section{Table 4}

Microscope images of corrosion spots found on the reflective layer and corresponding pinholes in the paint on the back of Type 1 silvered-glass reflectors after 20 Kesternich test cycles. All images are 10x, except for Test $K_{-} 1 \_25$, which are 5x.

\begin{tabular}{|c|c|c|c|c|c|}
\hline \multirow{2}{*}{ Defects } & \multicolumn{5}{|c|}{ Type 1 silvered-glass reflectors } \\
\hline & К 0.240 & K 125 & K 1140 & K 150 & K 240 \\
\hline Spots & & & 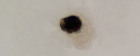 & & \\
\hline Pinholes & $\%$ & & & 48 & \\
\hline
\end{tabular}

More detailed characterization was done on the reflective area near the scratch, which was expected to be the most sensitive part of the reflectors. First, monochromatic specular reflectance results are plotted over the number of Kesternich cycles in Fig. 5, showing that the tests without gas did not cause any significant change in this parameter. However, all the aging conditions with $\mathrm{SO}_{2}$ show a similar downward trend up to a maximum decrease of $0.097 \pm 0.015,-0.093 \pm 0.014,-0.081 \pm 0.012$ and $-0.115 \pm 0.004$ for the Tests K_0.2_40, K_1_25, K_1_40 and K_2_40, respectively. Test K_1_50 caused the greatest fall in specular reflectance (up to $-0.214 \pm 0.032$ after 20 cycles).

These significant reductions in reflectance were also corroborated by microscopic examination of the scratch. As may be seen in Table 5, the mean increment in scratch width $(\Delta W)$ is higher at the end of the tests with the most decrease in reflectance, which also show more corrosion. Again, the increment in scratch width (between 1200 and $1600 \mu \mathrm{m}$ ) is similar in Tests K_0.2_40, K_1_25, K_1_40 and K_2_40. On the contrary, in Test $\mathrm{K} \_1 \_50$, the scratch is so corroded that it is complicated to measure its width properly at the same magnification, as it increased by over $2000 \mu \mathrm{m}$. The maximum increase in width in the $\mathrm{SO}_{2}$-free humidity tests is at least one order of magnitude lower than their counterparts in the Kesternich tests. The evolution of the mean increment in scratch width (in $\mu \mathrm{m}$ ) in the tests is shown over the number of cycles in Fig. 6. Agreement between these results and the evolution of monochromatic specular reflectance shown in Fig. 5 is very good.

As shown in these figures, the weathering tests were classified as very low corrosion (K_0_25, K_0_40 and K_0_50), medium corrosion (K_0.2_40, K_1_25, K_1_40 and K_2_40) and high corrosion (K_1_50). Nevertheless, taking into account the corrosion features in the rest of the reflector area (Table 3), Tests K_0.2_40 and K_2_40 may be regarded as low and high, respectively. Therefore, although the corrosion severity of the tests without $\mathrm{SO}_{2}$ is very low, and becomes more significant as the testing temperature rises, in the experiments with gas, the corrosion is much stronger, especially at high $T$ and gas concentrations. 


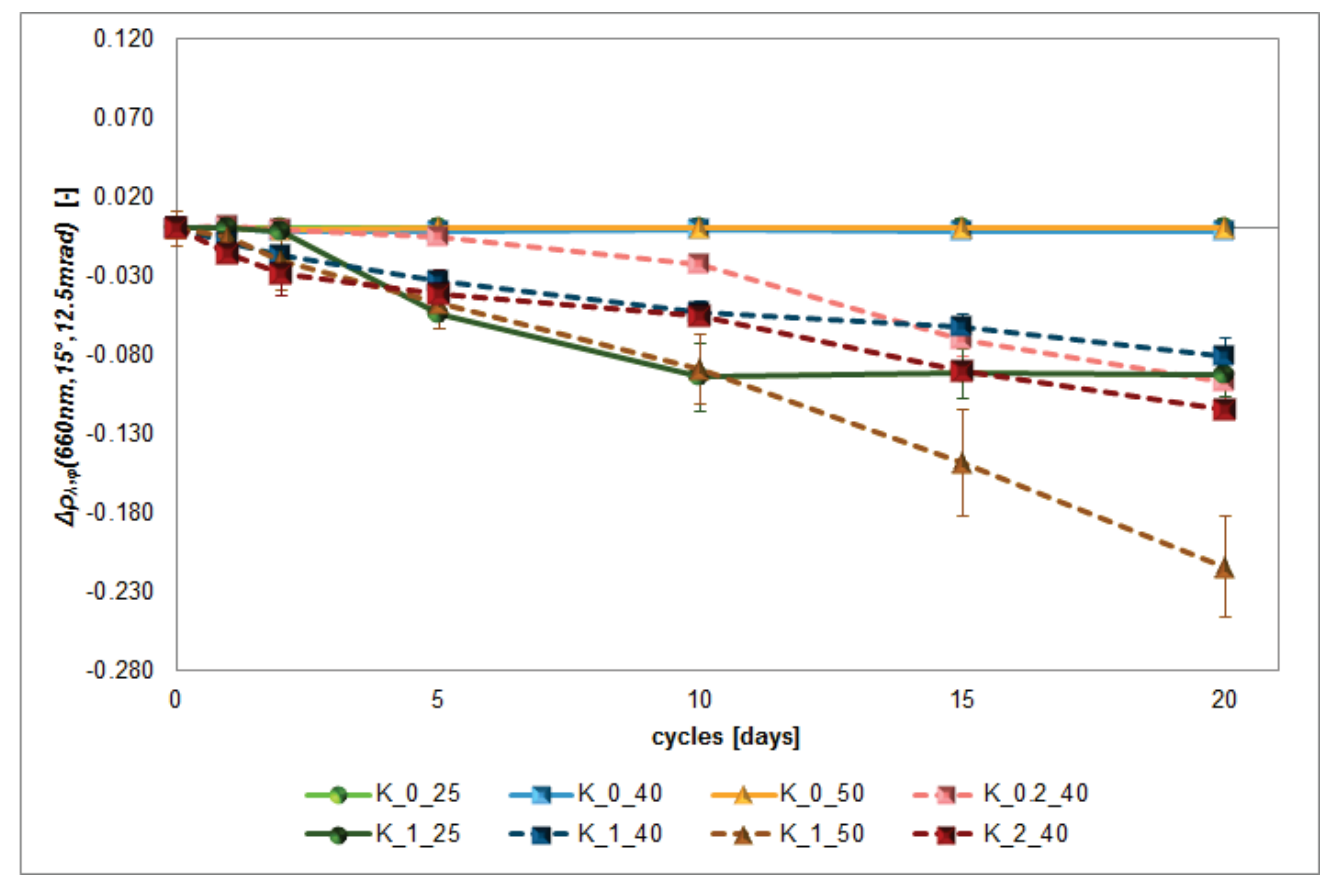

Fig. 5. Evolution over 24-hour cycles of the mean increment in monochromatic specular reflectance measured in the area of the scratch in Type 1 silvered-glass reflectors in the weathering tests.

\section{Table 5}

Summary of corrosion found in the area near the scratch on Type 1 silvered-glass reflectors after 20 aging cycles in all tests. $\Delta W$ : mean increment in scratch width $(\mu \mathrm{m}), \Delta \rho_{\lambda, \varphi}$ : mean increment in monochromatic specular reflectance in the scratch (-). All microscope images are $5 x$.

\begin{tabular}{|c|c|c|c|c|}
\hline \multicolumn{5}{|c|}{ Scratches on Type 1 silvered-glass reflectors } \\
\hline Test & K_0_25 & K_0_40 & K_0_50 & K_0.2_40 \\
\hline $\begin{array}{c}\text { Microscope } \\
\text { image }\end{array}$ & & & & \\
\hline $\boldsymbol{\Delta} \boldsymbol{W}(\boldsymbol{\mu} \mathbf{m})$ & $+91.5 \pm 0.0$ & $+153.7 \pm 0.0$ & $+108.9 \pm 0.0$ & $+1207.2 \pm 93.9$ \\
\hline $\boldsymbol{\Delta} \boldsymbol{\rho}_{\lambda, \varphi}(-)$ & $0.000 \pm 0.000$ & $-0.002 \pm 0.001$ & $0.001 \pm 0.000$ & $-0.097 \pm 0.015$ \\
\hline Test & K_1_25 & K_1_40 & K_1_50 & K_2_40 \\
\hline
\end{tabular}




\begin{tabular}{|c|c|c|c|c|}
\hline $\begin{array}{c}\text { Microscope } \\
\text { image }\end{array}$ & & & & \\
\hline $\boldsymbol{\Delta} \boldsymbol{W}(\boldsymbol{\mu m})$ & $+1411.7 \pm 719.8$ & $+1465.6 \pm 173.3$ & $+2007.1 \pm 224.8$ & $+1571.6 \pm 165.1$ \\
\hline $\boldsymbol{\Delta} \boldsymbol{\rho}_{\lambda, \varphi}(-)$ & $-0.093 \pm 0.014$ & $-0.081 \pm 0.012$ & $-0.214 \pm 0.032$ & $-0.115 \pm 0.004$ \\
\hline
\end{tabular}

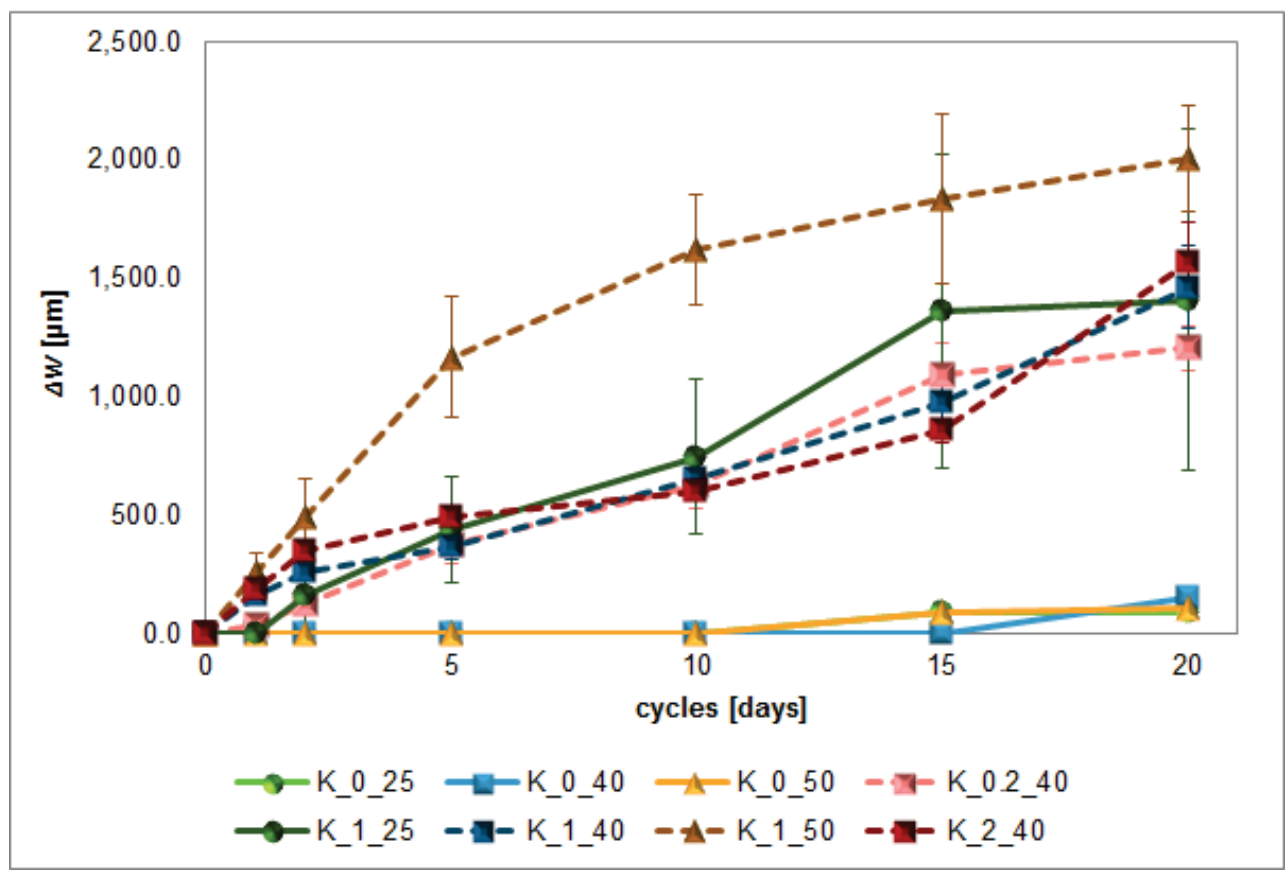

Fig. 6. Evolution of the mean scratch width increment $(\mu \mathrm{m})$ on Type 1 silvered-glass reflectors during cycles in the different corrosion tests.

\subsection{Undamaged silvered-glass reflectors (Type 2)}

As in the first reflector material studied, monochromatic specular and hemispherical reflectance was also measured on the whole undamaged reflective area of Type 2 silvered-glass reflectors, as plotted over the number of cycles in Figs. 7left and right. No decrease in reflectance was observed after the humidity tests without gas, except for Test K_0_50, which was responsible for a loss of $-0.006 \pm 0.000$ in specular reflectance. There was no significant reduction in reflectance either in K_0.2_40, K_1_25 or K_1_40 (classified as low and medium corrosion tests for Type 1 silvered-glass reflectors). However, the K_1_50 and K_2_40 high corrosion tests did cause a major decrease in both specular and hemispherical reflectance, especially after 20 cycles of Test K_2_40, in which there was a loss of $-0.635 \pm 0.153$ in specular reflectance. Such strong reductions in reflectance of previously undamaged silvered-glass reflectors have not been reported for accelerated aging tests with corrosive gas [31]. Therefore, the Kesternich test can be regarded as a very aggressive corrosion test for silvered-glass reflectors, especially when extreme conditions of gas concentration or temperature are selected. 

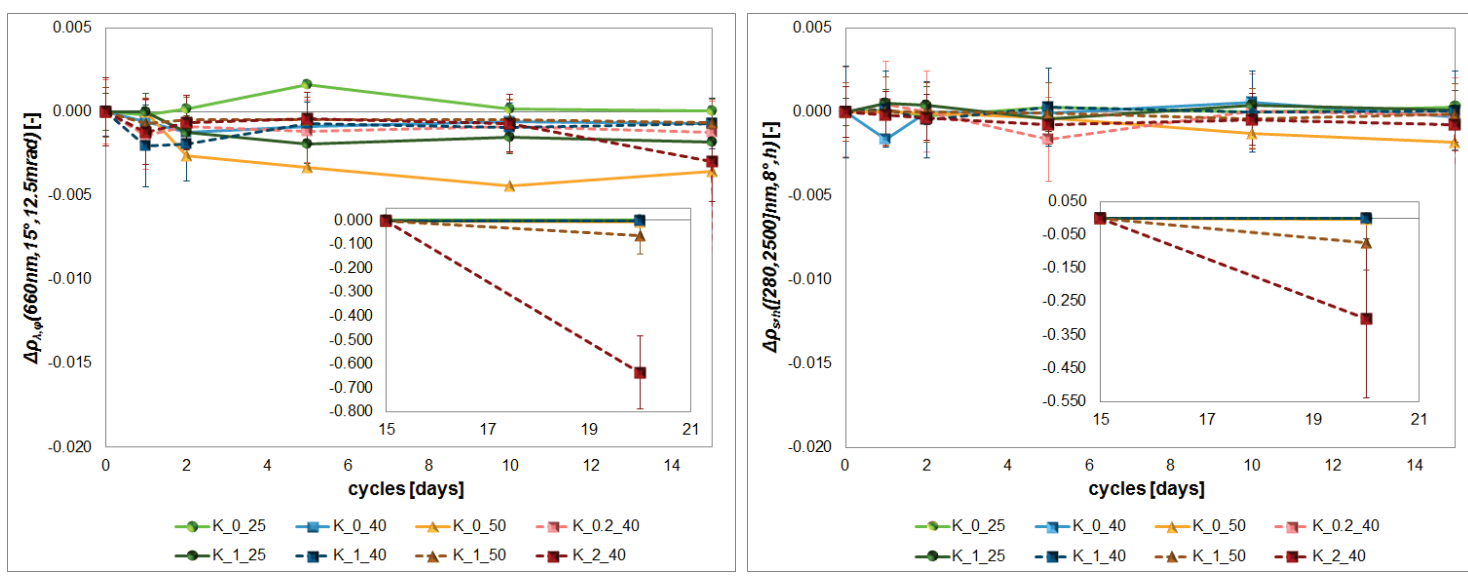

Fig. 7. Mean increment in monochromatic specular reflectance (left) and in solar-weighted hemispherical reflectance (right) over the whole reflective area of Type 2 silvered-glass reflectors during weathering test cycles.

The reflectance results were confirmed by microscopic examination. Table 6 summarizes the most important corrosion defects found on the reflective layer of Type 2 silvered-glass reflectors at the end of testing (20 cycles). It may be seen that $\mathrm{K} \_0.2 \_40, \mathrm{~K} \_1 \_25$ and $\mathrm{K} \_1 \_40$ caused similar corrosion on the reflective layers with total corroded areas of $(0.7 \pm 0.1) \%$, $(1.5 \pm 0.3) \%$ and $(1.0 \pm 0.2) \%$, respectively. However, after K_1_50, abundant corrosion spots (67) appeared, more corrosion developed near the original edges (almost $1 \mathrm{~mm}$ ) and $(2.5 \pm 1.4) \%$ of total corrosion. Finally, the most dramatic changes were found after the test with the highest $\mathrm{SO}_{2}$ concentration (K_2_40). The many (370) large spots that appear on the reflective area of the specimens and the extreme mean size of the corroded area, $(35.8 \pm 5.3) \%$, provide good evidence of its highly corrosive character, as shown by the optical microscope images and the picture of the whole sample in Table 6. Finally, the tests without gas barely generated any corrosion on the samples, but did cause the formation of a significant number of blisters on the painted side of the reflectors (see Fig. 8). As discussed above for Type 1 silvered-glass reflectors, these blisters may evolve into pinholes when $\mathrm{SO}_{2}$ gas is added to the test environment. Several corrosion spots and their corresponding pinholes in the paint on the back of the reflector are displayed in Table 7.

\section{Table 6}

Summary of corrosion found on the reflective area of Type 2 silvered-glass reflectors after 20 cycles of all weathering tests. Total $N$ : sum of the number of corrosion spots visible to the naked eye at the end of testing on a $300-\mathrm{cm}^{2}$ total reflector surface, Size: characteristic length of the largest spot $(\mu \mathrm{m})$, Max. Pen.: maximum penetration of corrosion near the edge $(\mu \mathrm{m}), \Delta \rho_{\lambda, \varphi}$ : mean increment in monochromatic specular reflectance on the whole reflector surface (-), Total Corr.: mean total corrosion of the whole reflector surface (\%). 5x microscope images of the spots and 10x of original edges. 


\begin{tabular}{|c|c|c|c|c|c|c|c|c|c|}
\hline \multirow{2}{*}{\multicolumn{2}{|c|}{$\begin{array}{l}\text { Corrosion } \\
\text { features }\end{array}$}} & \multicolumn{8}{|c|}{ Reflective area of Type 2 silvered-glass reflectors } \\
\hline & & K_0_25 & K_0 40 & K_0_50 & K_0.2_40 & K_1_25 & K_1_40 & K_1_50 & K_2_40 \\
\hline \multirow{3}{*}{ 产 } & Image & -- & -- & -- & a & & 4 & & \\
\hline & Total $N$ & 0 & 0 & 0 & 26 & 28 & 29 & 67 & 370 \\
\hline & $\begin{array}{l}\text { Size } \\
\text { (uIm) }\end{array}$ & -- & -- & -- & 1092 & 1251 & 1112 & 1002 & 2339 \\
\hline \multirow{2}{*}{ 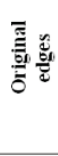 } & Image & & & & & & & & \\
\hline & $\begin{array}{l}\text { Max. } \\
\text { Pen. } \\
\text { (uim) }\end{array}$ & No corrosion & No corrosion & No corrosion & 500 & 901 & 788 & 937 & $\mathrm{~cm}$ order \\
\hline \multirow{3}{*}{ 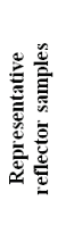 } & $\begin{array}{c}\text { Photo } \\
(10 \times 10) \\
\mathrm{cm}^{2} \\
\text { sample }\end{array}$ & & & & & & & 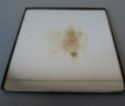 & \\
\hline & $\Delta \rho_{\text {i, }}(-)$ & $0.000 \pm 0.000$ & $-0.001 \pm 0.000$ & $-0.006 \pm 0.000$ & $-0.001 \pm 0.002$ & $-0.002 \pm 0.001$ & $-0.001 \pm 0.001$ & $-0.064 \pm 0.076$ & $-0.635 \pm 0.153$ \\
\hline & $\begin{array}{l}\text { Total } \\
\text { Corr. } \\
(\mathbf{\%})\end{array}$ & $0.0 \pm 0.0$ & $0.0 \pm 0.0$ & $0.0 \pm 0.0$ & $0.7 \pm 0.1$ & $1.5 \pm 0.3$ & $1.0 \pm 0.2$ & $2.5 \pm 1.4$ & $35.8 \pm 5.3$ \\
\hline
\end{tabular}
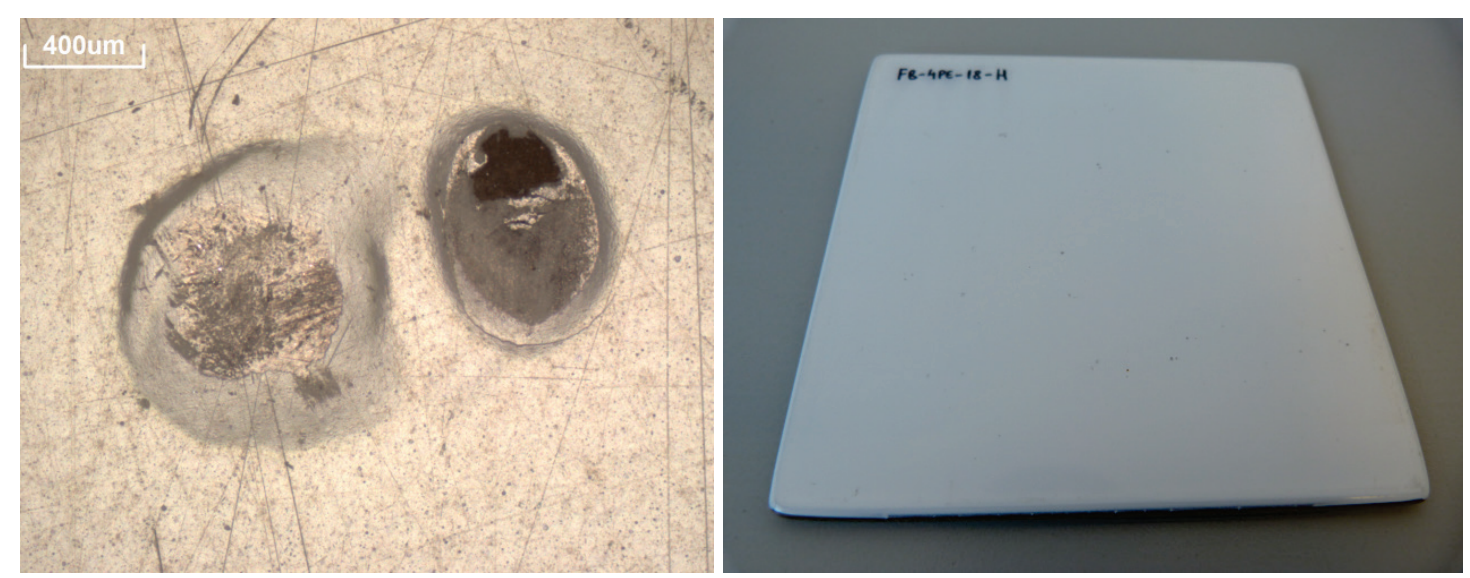

Fig. 8. 5x microscope image of blisters found in the paint on the back of a Type 2 silvered-glass reflector sample after 20 cycles of the K_0_40 humidity test (left), picture of the appearance of blisters at naked eye (right).

\section{Table 7}

10x microscope images of corrosion spots found on the reflective layer and corresponding pinholes in the paint on the back of Type 2 silvered-glass reflectors after 20 Kesternich test cycles.

\begin{tabular}{|c|c|c|c|c|c|}
\hline \multirow{2}{*}{ Defects } & \multicolumn{5}{|c|}{ Type 2 silvered glass reflectors } \\
\hline & K_0.2_40 & K_1_25 & K_1_40 & K_1_50 & K_2_40 \\
\hline Spots & & & & & \\
\hline
\end{tabular}




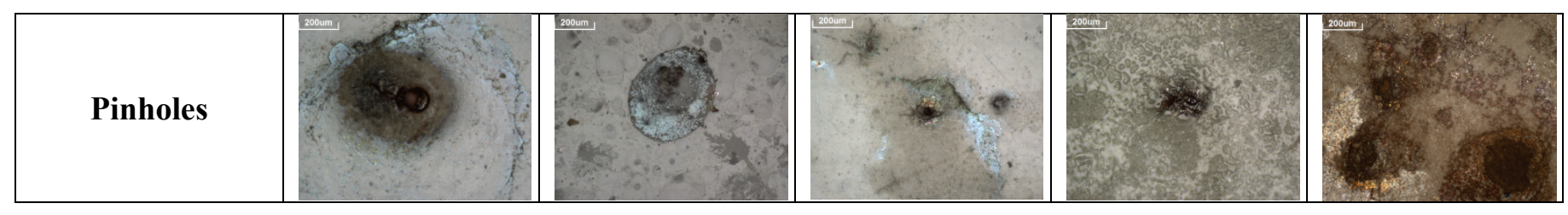

Summarizing, while the tests with low and moderate gas concentration and temperature conditions (K_0.2_40, K_1_25 and K_1_40) were responsible for moderate degradation of samples, the tests with the highest $\left[\mathrm{SO}_{2}\right]$ or $T$, i.e. Tests $\mathrm{K} \_1 \_50$ and $\mathrm{K} \_2 \_40$, led to massive corrosion, both on the reflective and painted layers of the undamaged silvered-glass reflectors. However, the humidity tests without gas (K_0_25, K_0_40 and K_0_50) did not significantly alter their properties. $\mathrm{SO}_{2}$ corrosion defects were the same sort as in the studies of predamaged silvered-glass reflectors, and the general conclusions drawn are also similar. Comparing the percentage of total area corroded on both reflector types (see Tables 3 and 6), degradation of the undamaged materials at the end of every test was less than on the predamaged ones, except for the most aggressive test (K_2_40). This is because Type 2 reflectors have larger corrosion spots and more of them than Type 1 in most tests, whereas in the latter, both cut and original edges were in poorer condition. The results also suggest stronger influence of the high $\mathrm{SO}_{2}$ concentration than temperature in silvered-glass reflector degradation. Moreover, it is important to highlight that the two types of reflectors were fabricated by the same manufacturer and had the same reflective and paint-layer structure, but Type 1 reflectors were industrial, whereas Type 2 were manufactured to order on a small scale. These findings therefore show the strong influence of material processing on the final properties of reflectors. Thus subtle differences in layer composition (due to different amounts of impurities) or structure (grain size, porosity, film homogeneity or thickness, etc.) may be responsible for the significantly higher corrosion observed at high $\mathrm{SO}_{2}$ concentrations in Type 2 reflectors than in Type 1.

\subsection{Predamaged aluminum reflectors (Type 3)}

The third type of solar reflector was studied following a procedure similar to those above. First, monochromatic specular and hemispherical reflectance on the undamaged reflective area of samples was monitored during the tests. Results are shown in Fig. 9, where the greatest decrease in specular reflectance $(-0.008 \pm 0.016)$ was found after Test K_2_40 (Fig. 9left). No significant reduction in reflectance was detected in the rest of tests, although there was an anomalous loss of $-0.006 \pm 0.000$ in specular reflectance within the range of experimental errors for the test at $40{ }^{\circ} \mathrm{C}$ without gas (K_0_40). There was no significant decrease in solar-weighted hemispherical reflectance as shown in Fig. 9right. 


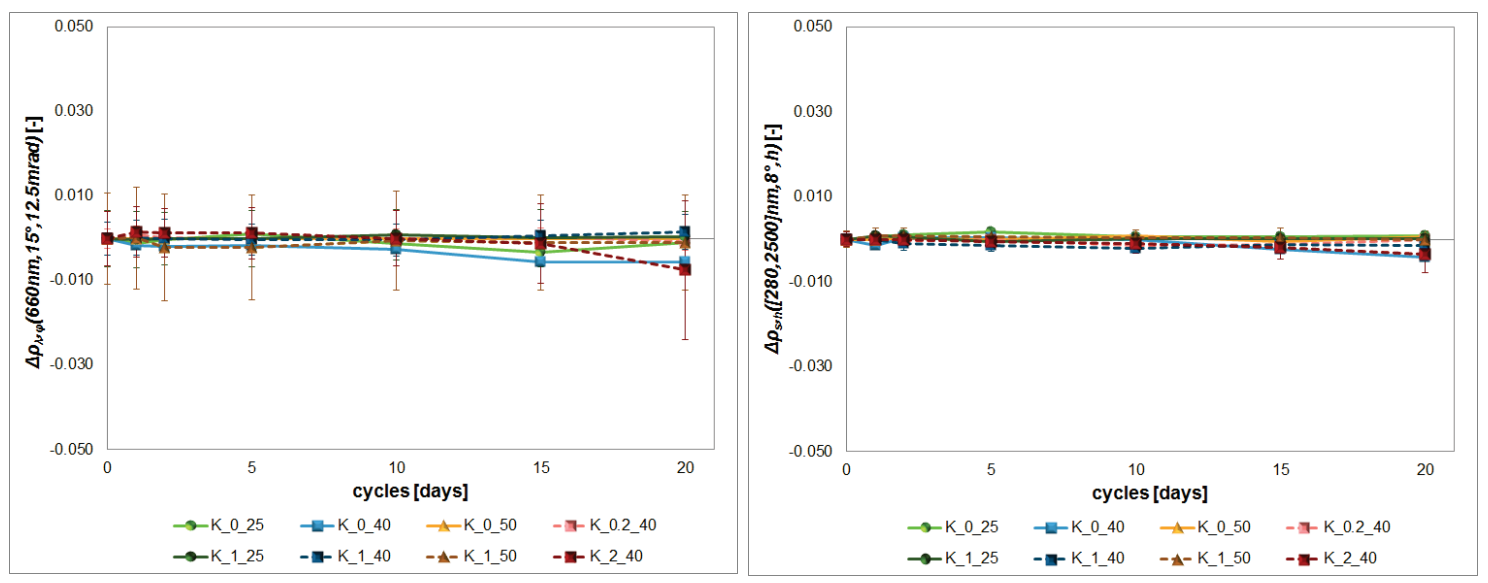

Fig. 9. Evolution of the mean increment in monochromatic specular reflectance (left) and solarweighted hemispherical reflectance (right) during weathering test cycles on the originally undamaged areas of aluminum reflectors.

Table 8 is an overview of the most significant corrosion features found on the reflective layer of aluminum reflectors at the end of testing. As previously pointed out, optical microscope results provide a more detailed view of the real state of corrosion than the reflectance data. There was no change in the microscopic features of samples after the humidity tests (K_0_25, K_0_40, $\mathrm{K} \_$0_50) or the low corrosion test (K_0.2_40). However, visible black spots appeared on the reflective surface of materials after the medium $\left(\mathrm{K} \_1\right.$ 125, $\left.\mathrm{K} \_1 \_40\right)$ and high $\left(\mathrm{K} \_1\right.$ 1 50, $\left.\mathrm{K} \_2 \_40\right)$ corrosion tests. Bare edges thickened noticeably. The most harmful test was K_ 2 _ 40 , as demonstrated by the total number of corrosion spots (681) and the general appearance of the reflector surface. Therefore, test aggressiveness for aluminum reflectors observed under the microscope is in general agreement with what was found for the reflector types discussed above.

\section{Table 8}

Summary of corrosion found on the reflective area of the aluminum reflectors after 20 cycles of all weathering tests. Total $N$ : sum of the number of corrosion spots visible to the naked eye at the end of testing on a $300-\mathrm{cm}^{2}$ total reflector surface, Size: characteristic length of the largest spot $(\mu \mathrm{m})$, Max. Pen.: maximum penetration of corrosion near the edge $(\mu \mathrm{m}), \Delta \rho_{\lambda, \varphi}$ : mean increment in monochromatic specular reflectance on reflector surfaces not predamaged (-), Total Corr.: mean total corrosion of the whole reflector surface (\%). Microscope images are $10 \mathrm{x}$. 


\begin{tabular}{|c|c|c|c|c|c|c|c|c|c|}
\hline \multirow{2}{*}{\multicolumn{2}{|c|}{$\begin{array}{c}\text { Corrosion } \\
\text { features }\end{array}$}} & \multicolumn{8}{|c|}{ Reflective area of aluminum reflectors } \\
\hline & & K_0_25 & K_0_40 & K_0 50 & K $0.2 \_40$ & K_1_25 & K_1_40 & K_1_50 & K_2_40 \\
\hline \multirow{3}{*}{$\frac{n}{2}$} & Image & -- & -- & -- & -- & & & & \\
\hline & Total $N$ & 0 & 0 & 0 & 0 & 47 & 100 & 225 & 681 \\
\hline & $\begin{array}{c}\text { Size } \\
\text { (IIIm) }\end{array}$ & -- & -- & - & -- & 505 & 590 & 854 & 760 \\
\hline \multirow{2}{*}{ 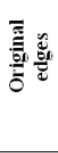 } & Image & & & & & & & & \\
\hline & $\begin{array}{l}\text { Max. } \\
\text { Pen. } \\
\text { (uIm) }\end{array}$ & No corrosion & No corrosion & No corrosion & 91 & 251 & 437 & 574 & 437 \\
\hline \multirow{3}{*}{ 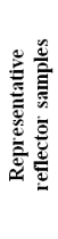 } & $\begin{array}{c}\text { Photo } \\
(12 \times 12) \\
\mathrm{cm}^{2} \\
\text { sample }\end{array}$ & & & & & & & & \\
\hline & $\Delta \rho_{\text {ine }}(-)$ & $-0.001 \pm 0.000$ & $-0.006 \pm 0.000$ & $0.000 \pm 0.000$ & $-0.001 \pm 0.002$ & $0.000 \pm 0.006$ & $0.002 \pm 0.004$ & $-0.001 \pm 0.011$ & $-0.008 \pm 0.016$ \\
\hline & $\begin{array}{l}\text { Total } \\
\text { Corr. } \\
(\%)\end{array}$ & $0.0 \pm 0.0$ & $0.0 \pm 0.0$ & $0.0 \pm 0.0$ & $1.3 \pm 0.2$ & $1.9 \pm 0.5$ & $3.8 \pm 0.2$ & $3.8 \pm 0.5$ & $5.1 \pm 1.1$ \\
\hline
\end{tabular}

Several parameters of the scratch were analyzed in more detail, the same as for Type 1 silveredglass reflectors. Thus, monochromatic specular reflectance was measured in the area of the scratch during the tests as shown in Fig. 10. Whereas Tests K_0_25, K_0_40, K_0_50, K_0.2_40, K_1_25 and K_1_40 did not modify reflectance, K_1_50 and K_2_40 were responsible for monochromatic specular reflectance reductions of $-0.005 \pm 0.012$ and $0.013 \pm 0.014$ in the scratch, respectively. The severity of the high corrosion tests is also confirmed by microscopic measurements of the scratch width (see Table 9 and Fig. 11). The largest changes in scratch width were found after K_2_40 and K_1_50, followed by K_1_40 and K_0.2_40. However, no significant modifications in scratch width were observed after the rest of the tests, even those without gas and the K_1_25 test, in spite of the spots that were observed at the end of this ambient temperature test with a medium $\mathrm{SO}_{2}$ concentration (see Table 9).

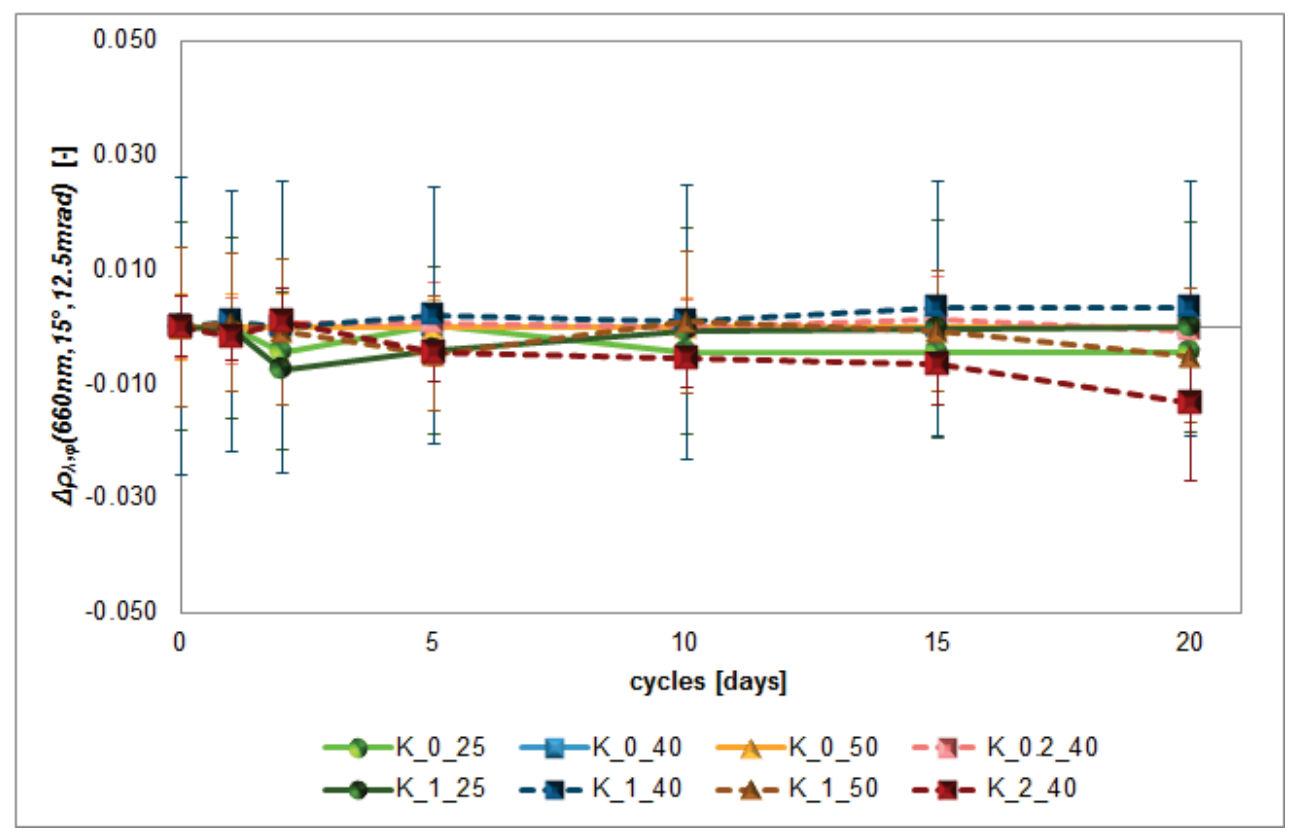

Fig. 10. Evolution of the mean increment in monochromatic specular reflectance over 24-hour cycles measured in the area of the scratch on aluminum reflectors in the weathering tests. 


\section{Table 9}

Summary of corrosion found in the area near the scratch on aluminum reflectors after 20 aging cycles in all tests. $\Delta W$ : mean increment in scratch width $(\mu \mathrm{m}), \Delta \rho_{\lambda, \varphi}$ : mean increment in monochromatic specular reflectance in the scratch (-). All microscope images are 10x.

\begin{tabular}{|c|c|c|c|c|}
\hline \multicolumn{5}{|c|}{ Scratches on aluminum reflectors } \\
\hline Test & K_0_25 & K_0_40 & K_0_50 & K_0.2_40 \\
\hline $\begin{array}{l}\text { Microscope } \\
\text { image }\end{array}$ & & & & \\
\hline$\Delta W(\mu \mathrm{m})$ & $0.0 \pm 0.0$ & $0.0 \pm 0.0$ & $+0.9 \pm 0.0$ & $+20.7 \pm 18.5$ \\
\hline$\Delta \rho_{\lambda, \varphi}(-)$ & $-0.001 \pm 0.001$ & $-0.001 \pm 0.000$ & $0.000 \pm 0.000$ & $-0.001 \pm 0.004$ \\
\hline Test & K_1_25 & K_1_40 & K_1_50 & K_2_40 \\
\hline $\begin{array}{l}\text { Microscope } \\
\text { image }\end{array}$ & & & & \\
\hline$\Delta W(\mu \mathrm{m})$ & $0.0 \pm 0.0$ & $+22.3 \pm 28.7$ & $+38.4 \pm 25.8$ & $+39.4 \pm 28.8$ \\
\hline$\Delta \boldsymbol{\rho}_{\lambda, \varphi}(-)$ & $0.000 \pm 0.018$ & $0.003 \pm 0.022$ & $-0.005 \pm 0.012$ & $-0.013 \pm 0.014$ \\
\hline
\end{tabular}




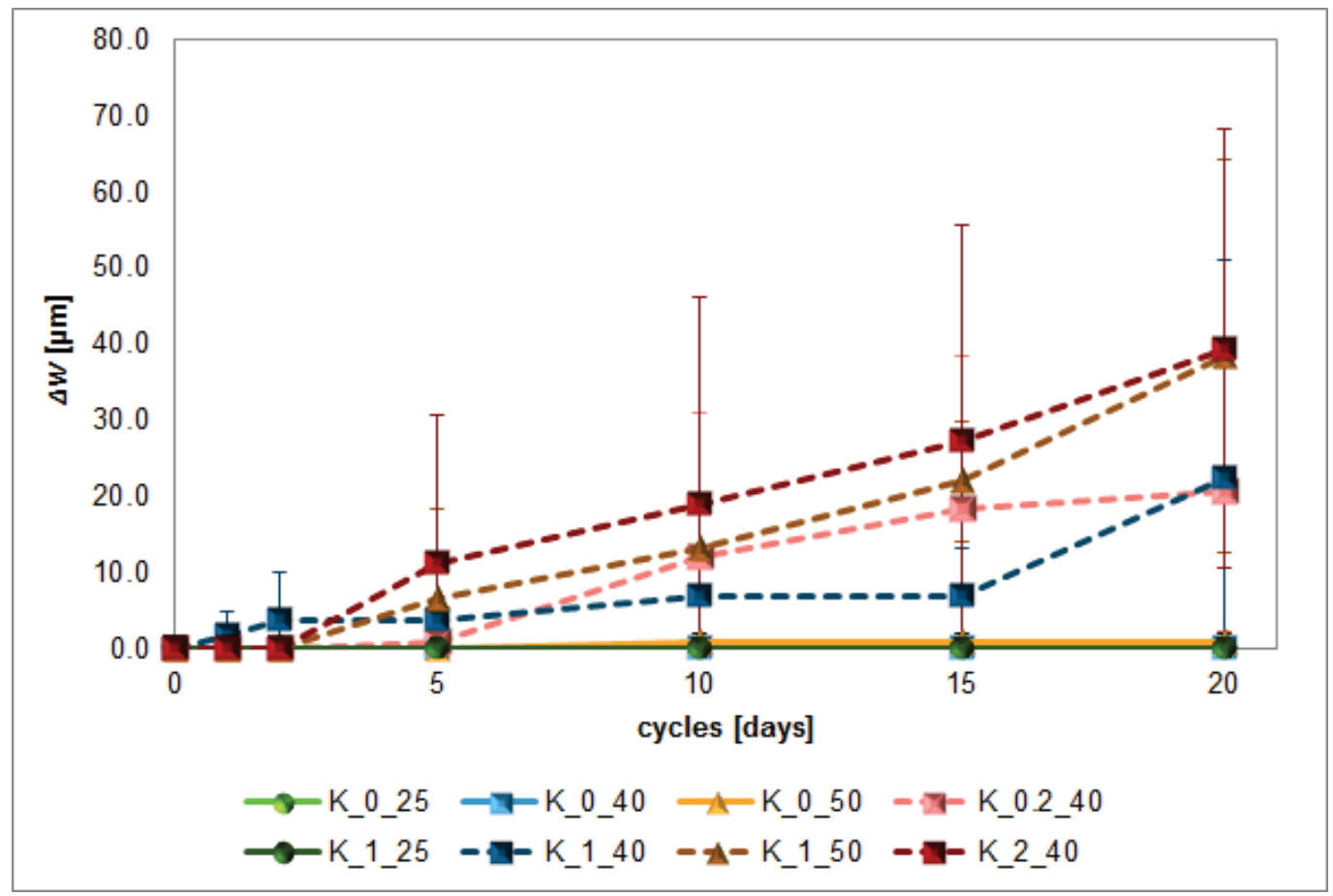

Fig. 11. Evolution of the mean increment in scratch width $(\mu \mathrm{m})$ in aluminum reflectors over corrosion test cycles.

Summarizing, aluminum reflectors were generally not as corroded by the Kesternich tests as silvered-glass reflectors. As reported in previous studies, degradation of aluminum reflectors is rather slow, mostly because of their protective $\mathrm{SiO}_{2}$ layer [23], and entails various factors including moisture, abrasion and pollutants during long exposure [13]. In this study, only the two extreme tests $\left(\mathrm{K}_{-} 2 \_40\right.$, with the highest $\mathrm{SO}_{2}$ concentration, and $\mathrm{K} \_1 \_50$, with the highest temperature) caused any corrosion detectable under the microscope, but it was harder to detect by monochromatic specular reflectance. In light of these results, both the corrosive gas concentration and its synergism with temperature and humidity are key factors to be considered in aluminum reflector durability studies, as the most corrosion was found in the test with the highest gas concentration and intermediate temperature (K_2_40).

\subsection{Comparisons with real outdoor data}

The most informative and aggressive test (K_2_40) was compared to real data from corroded mirror facets at a commercial CSP plant near an industrial site ${ }^{\dagger}$. After three years of exposure at this site, the PTC facets were inspected, and a mean pitting corrosion area of $0.16 \%$ was estimated. Both the Type 1 silvered-glass reflectors and the samples from this commercial CSP plant were from industrial PTC facets made by the same manufacturer and have the same layered structure. Indeed, corrosion spots found on Type 1 silvered-glass reflectors were very similar to the on-site facets, as shown in Fig. 12. Type 2 silvered-glass reflectors, however, although by the same manufacturer, were specifically manufactured at small scale in a $10 \times 10 \mathrm{~cm}^{2}$ format, and hence, these results are not comparable.

\footnotetext{
${ }^{\dagger}$ The exact location cannot be revealed due to confidentiality of information
} 

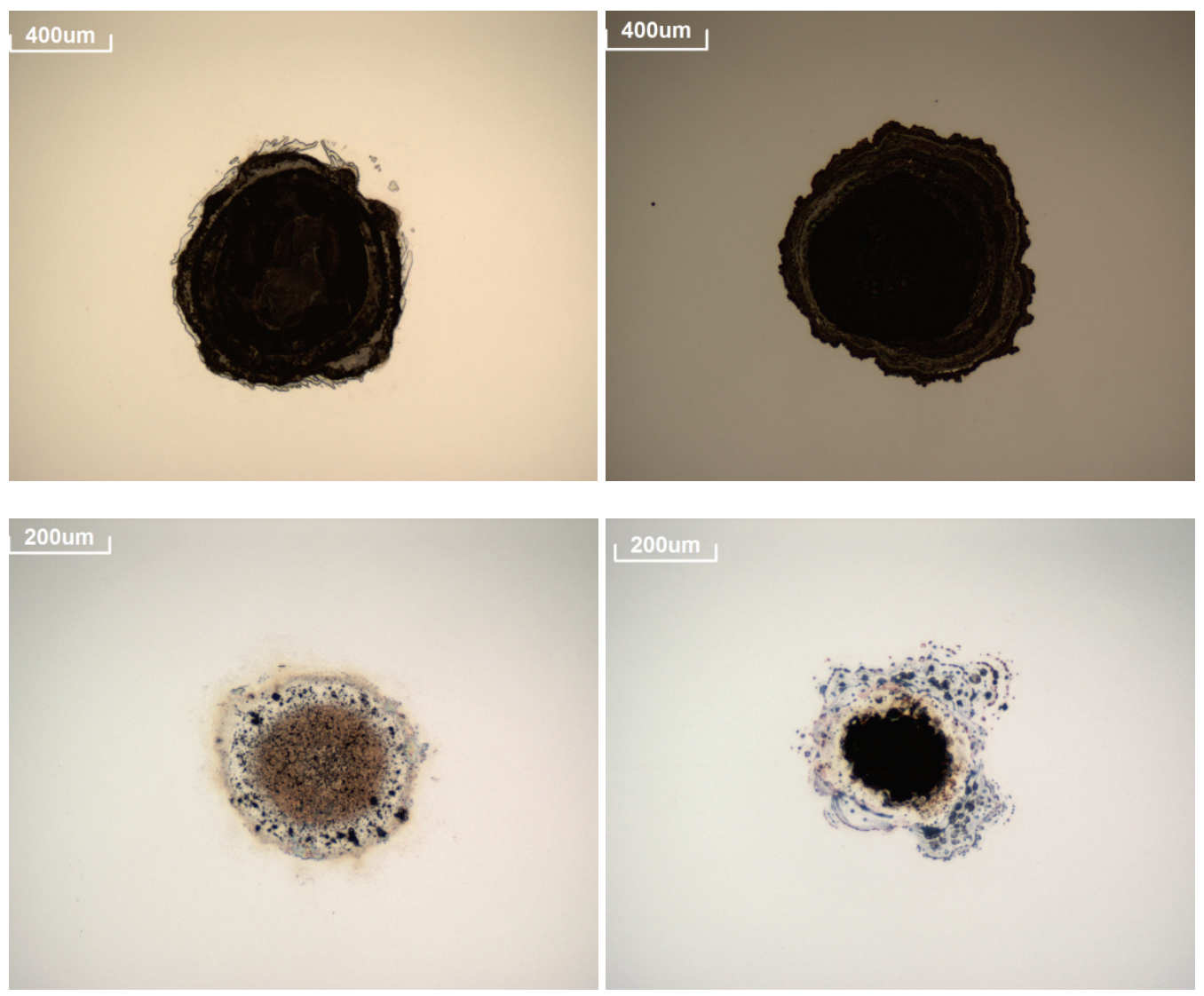

Fig. 12. Microscope images of corrosion spots on Type 1 silvered-glass reflectors in on-site PTC facets after 20 cycles of Test K_2_40 (left) and after three years at a commercial CSP plant near an industrial site (right).

The growth of corrosion spots on Type 1 silvered-glass reflectors was monitored during the K_2_40 test cycles by microscopic measurement. Thus, the areas of representative spots could be calculated, and by combining them with the total number of spots, the mean corroded area (per three specimens during the test cycles) was arrived at. Fig. 13 shows the mean area of corrosion spots (\%) on Type 1 silvered-glass reflectors over the number of test cycles. The measurements are marked with orange circles and the solid line is the best fit found with a determination coefficient of 0.9997 , which corresponds to an exponential function as shown in Eq. (1):

$$
y=7 \cdot 10^{-5} \exp [0.4048 x]
$$




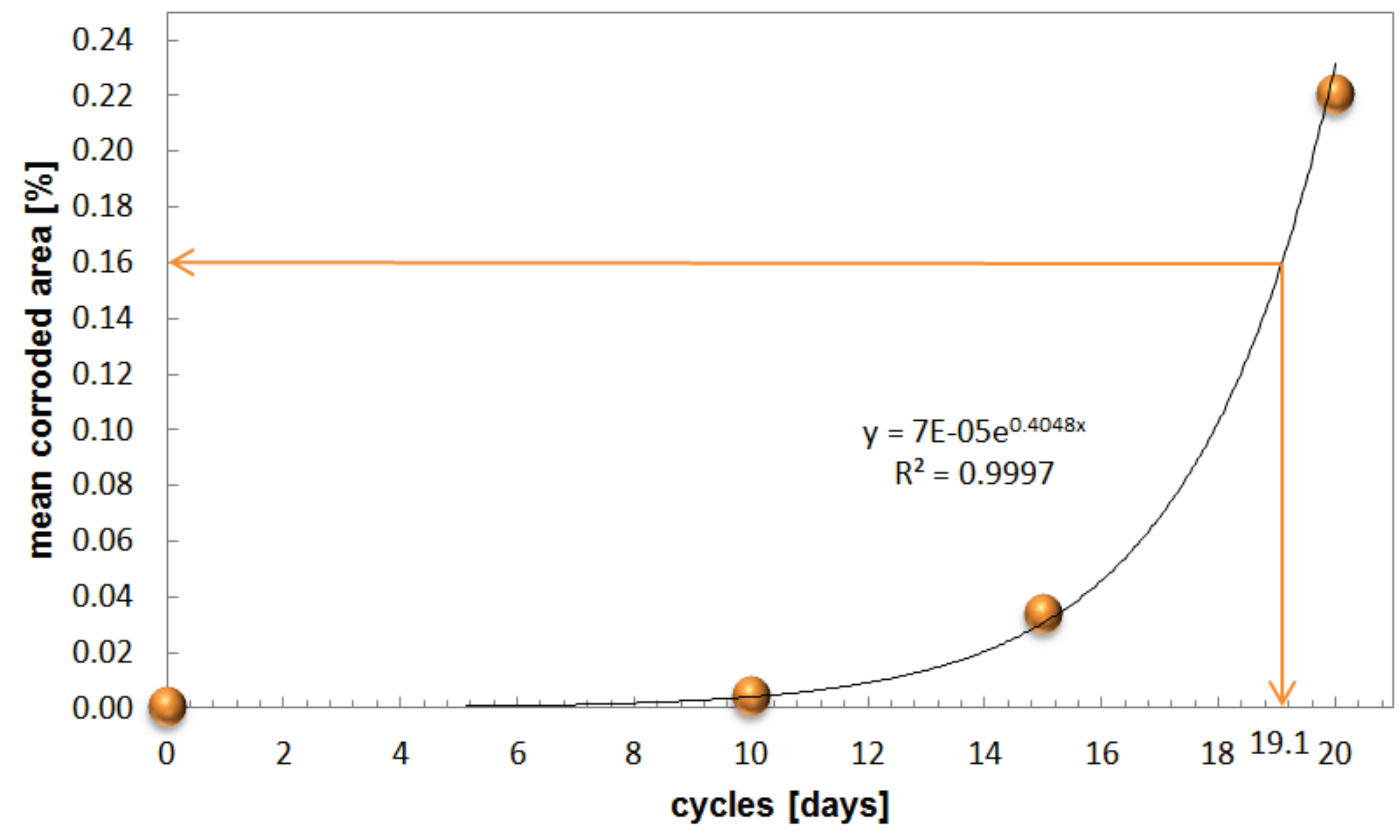

Fig. 13. Growth of mean area of corrosion spots (\%) on Type 1 silvered-glass reflectors during K_2_40 test cycles.

This correlation enabled the K_2_40 test time (24-hour cycles) equivalent to real on-site degradation to be found, i.e. $0.16 \%$ after 19.1 test cycles $(458 \mathrm{~h}$ ), as marked with orange arrows in Fig. 13. As the real exposure time was three years, the acceleration factor would be 57 for the study exposure site. These rough calculations, which are a first step in the correlation of accelerated tests with real outdoor exposures, may be very valuable, since such estimates for commercial CSP silvered-glass reflectors are rarely found in the literature.

\section{Conclusions}

Solar reflectors for CSP applications were subjected to humid atmospheres containing $\mathrm{SO}_{2}$ in accelerated aging tests simulating aggressive industrial environments. Based on Kesternich test methods, three types of commercial reflector materials were weathered in water-saturated $\mathrm{SO}_{2}$ atmospheres at several temperatures and concentrations and with no $\mathrm{SO}_{2}$. The tests were monitored by reflectance measurements and by examination under optical microscope.

Predamaged silvered-glass reflectors (Type 1) showed no significant reduction in reflectance on originally undamaged areas. However, microscopic inspection revealed major degradation of both the whole surface and scratch after the most aggressive tests $\left(1.0 \mathrm{dm}^{3} \mathrm{SO}_{2}\right.$ at $50^{\circ} \mathrm{C}$, $\mathrm{K} \_1550$; and $2.0 \mathrm{dm}^{3} \mathrm{SO}_{2}$ at $40^{\circ} \mathrm{C}, \mathrm{K} \_2 \_40$ ), the test at the highest gas concentration being more harmful than the one at the highest temperature. Corrosion spots appeared on the reflective silver layer and blisters that could turn into pinholes on the painted protective back layer, which were most noticeable in the $\mathrm{SO}_{2}$-free tests. The presence of a pinhole often triggers the formation of a corrosion spot. Therefore, the extreme K_2_40 test should be selected for significant results in a short time, although Test K_1_50 may be considered suitable for Type1 
silvered-glass reflectors, because it also gives representative results with a lower concentration of $\mathrm{SO}_{2}$, and is therefore more cost-effective and less environmentally hazardous.

Undamaged silvered-glass reflectors (Type 2), on the other hand, generally exhibited poorer performance than Type 1 reflectors. Although the latter had more corroded edges, Type 2 reflectors not only showed more, larger corrosion spots in most tests, but also underwent high specular reflectance losses of up to $-0.635 \pm 0.153$ at the end of the K_2_40 test. Small-size samples of this reflector type were specially manufactured at small scale and did not come from real PTC mirror facets as did the Type 1 reflector samples. Therefore, Kesternich tests at high gas concentrations or temperatures are considered too extreme, and more moderate conditions such as the K_1_40 test are recommended for more realistic Type 2 reflector results.

Finally, Type 3 predamaged aluminum reflectors were not as corroded as silvered-glass reflectors, but they underwent visible degradation, mainly as black spots on the reflective surface and scratch. Again, Test K____40 was the most corrosive due to its high $\mathrm{SO}_{2}$ concentration, but synergies with temperature and humidity are key factors that must be considered as well. Therefore, the K_2_40 test is recommended for aluminum reflectors. For low-concentrating systems where specularity is not the limiting factor (such as small PTCs for process heat applications) aluminum reflectors would be worthwhile because they can withstand highly corrosive acid atmospheres better than silvered-glass reflectors.

In addition, results from Test $\mathrm{K} \_2 \_40$ were compared to corrosion data from real on-site PTC facets located near an industrial environment. Microscopic defects found in Type 1 silveredglass reflectors were very similar to corrosion spots in the on-site facets. An estimated acceleration factor of 57 correlates Test K_2_40 with this real outdoor exposure affected by a highly polluted industrial atmosphere. This may be considered a valuable contribution to the service lifetime prediction of solar reflector materials, especially the widely deployed silveredglass reflectors.

The immediate implications of this study are its relevance to research in the effects of acid rain environments on other CSP components, such as PTC absorber tubes or open volumetric receivers in solar towers. Apart from the diversification of accelerating aging tests, this study aimed to highlight the importance of proper CSP facility siting, avoiding areas with highly polluted atmospheres near industrial sites if possible.

\section{Acknowledgments}

This study was carried out under the Spanish DETECSOL Project (grant ${ }^{\circ}$ ENE2014-56079-R) funded by the Ministerio de Economía y Competitividad [Ministry of Economy and Competitiveness] Programa Estatal de Investigación, Desarrollo e Innovación orientada a los Retos de la Sociedad [National Program for Research, Development and Innovation oriented to Society's Challenges]. Research leading up to this study also received funding from the EU Horizon 2020 - H2020-LCE-2016-2017 under grant agreement n 731287 (Integrating National Research Agendas on Solar Heat for Industrial Processes, INSHIP). The authors wish to thank Lucía Martínez-Arcos of CIEMAT, Tomás Jesús Reche-Navarro of DLR, Julio A. RabalEscarbajal of the UPV and Alba Hernández-Zanoletty of the University of Almería for their valuable contributions. 


\section{References}

[1] Renewables 2016 Global Status Report, Technical Report, ISBN 978-3-9818107-0-7, Renewable Energy Policy Network for 21st century, REN21 Secretariat, Paris, France, 2016.

[2] IEA, Technology roadmap: Solar thermal electricity, 2014.

[3] A. Jäger-Waldau, Photovoltaics and renewable energies in Europe, Renew. Sust. Energy Rev. 11 (2007) 1414-1437.

[4] F.G. Montoya, M.J. Aguilera, F. Manzano-Agugliaro, Renewable energy production in Spain: A review, Renew. Sust. Energy Rev. 33 (2014) 509-531.

[5] A. Fernández-García, R. Díaz-Franco, L. Martínez-Arcos, J. Wette, Study of the effect of acid atmospheres in solar reflectors durability under accelerated aging conditions, Energy Procedia 49 (2014) 1682-1691.

[6] M. Flues, P. Hama, M.J.L. Lemes, E.S.K. Dantas, A. Fornaro, Evaluation of the rainwater acidity of a rural region due to a coal-fired power plant in Brazil, Atmospheric Environ. 36 (2002) 2397-2404.

[7] R. Tsitouridou, C. Anatolaki, On the wet and dry deposition of ionic species in the vicinity of coal-fired power plants, northwestern Greece, Atmospheric Res. 83 (2007) 93-105.

[8] I. Hůnová, J. Maznová, P. Kurfürst, Trends in atmospheric deposition fluxes of sulphur and nitrogen in Czech forests. Environ. Pollut. 184 (2014) 668-675.

[9] C. Leygraf, T.E. Graedel, Atmospheric Corrosion, ECS Corrosion Monograph Series, Wiley Interscience, 2000.

[10] S. Henschel, X. Querol, R. Atkinson, M. Pandolfi, A. Zeka, A. Le Tertre, et al., Ambient air $\mathrm{SO}_{2}$ patterns in 6 European cities, Atmospheric Environ. 79 (2013) 236-247.

[11] B. Carlsson, K. Möller, U. Frei, S. Brunold, M. Köhl, Comparison between predicted and actually observed in-service degradation of a nickel pigmented anodized aluminum absorber coating for solar DHW systems, Sol. Energy Mater. Sol. Cells 61 (2000) 223-238.

[12] K. Slamova, I. Duerr, T. Kaltenbach, M. Koehl, Degradation effects of maritime atmosphere on metallic components of solar collectors, Sol. Energy Mater. Sol. Cells 147 (2016) 246-254.

[13] M. Brogren, B. Karlsson, A. Roos, A. Werner, Analysis of the effects of outdoor and accelerated ageing on the optical properties of reflector materials for solar energy applications, Sol. Energy Mater. Sol. Cells 82 (2004) 491-515.

[14] J. Wette, F. Sutter, A. Fernández-García, S. Ziegler, R. Dasbach, Comparison of degradation on aluminum reflectors for solar collectors due to outdoor exposure and accelerated aging, Energies 9 (2016) 916.

[15] P. Schissel, A.W. Czanderna, Reactions at the silver/polymer interface: A review, Sol. Energy Mater. 3 (1980) 225-245. 
[16] W.H.J. Vernon, A laboratory study of the atmospheric corrosion of metals. Part I.-The corrosion of copper in certain synthetic atmospheres, with particular reference to the influence of sulphur dioxide in air of various relative humidities, Trans. Faraday Soc. 27 (1931) 255-277.

[17] C. Kleber, U. Hilfrich, M. Schreiner, In situ QCM and TM-AFM investigations of the early stages of degradation of silver and copper surfaces, Appl. Surf. Sci. 253 (2007) 3712-3721.

[18] F. Sutter, A. Fernández-García, P. Heller, K. Anderson, G. Wilson, M. Schmücker, et al., Durability testing of silvered-glass mirrors, Energy Procedia 69 (2015) 1568-1577.

[19] ISO 9227:2017, Corrosion tests in artificial atmospheres -Salt spray tests, International Organization for Standardization (ISO), Geneva, 2017.

[20] J. Wette, F. Sutter, A. Fernández-García, Correlating outdoor exposure with accelerated aging tests for aluminum solar reflectors, AIP Conf. Proc. 1734 (2016) 090003-1-090003-8.

[21] A. García-Segura, A. Fernández-García, M.J. Ariza, F. Sutter, L. Valenzuela, Durability studies of solar reflectors: A review, Renew. Sustain. Energy Rev. 62 (2016) 453-467.

[22] R.T. Coyle, J.M. Barrett, P.J. Call, Durability of silver-glass mirrors in moist acid vapors, Sol. Energy Mater. 6 (1982) 351-373.

[23] R. Almanza, C. Jiefeng, G. Correa, M. Mazari, Further option for solar concentrators: Aluminum first surface mirrors, Sol. Energy 54 (1995) 333-343.

[24] ISO 6988:1985, Metallic and other non-organic coatings. Sulfur dioxide test with general condensation of moisture, International Organization for Standardization (ISO), Geneva, 1985.

[25] DIN 50018, Prüfung im Kondenswasser-Wechselklima mit schwefeldioxidhaltiger Atmosphäre (in English: "Testing in a saturated atmosphere in the presence of sulphur dioxide"), Deutsches Institut für Normung, e.V. (DIN), Berlin, 1997.

[26] N. Carmona, M.A. Villegas, J.M. Fernández Navarro, Corrosion behaviour of $\mathrm{R}_{2} \mathrm{O}-\mathrm{CaO}-$ $\mathrm{SiO}_{2}$ glasses submitted to accelerated weathering, J. Eur. Ceram. Soc. 25 (2005) 903-910.

[27] I. Szłapa, D. Jędrzejczyk, M. Hajduga, S. Węgrzynkiewicz, D. Sołek, Evaluation of corrosion resistance of zinc coatings on component of the ambulance. In: Metal 2013, 22nd International Conference on Metallurgy and Materials, Brno, 2013.

[28] O. García, K. Malaga, Definition of the procedure to determine the suitability and durability of an anti-graffiti product for application on cultural heritage porous materials, J. Cult. Herit. 13 (2012) 77-82.

[29] C.L. Sansom, P. Comley, P. King, H.J. Almond, C. Atkinson, E. Endaya, Predicting the effects of sand erosion on collector surfaces in CSP plants, Energy Procedia 69 (2015) 198-207.

[30] F. Sutter, A. Fernández-García, J. Wette, P. Heller, Comparison and evaluation of accelerated aging tests for reflectors, Energy Procedia 49 (2014) 1718-1727.

[31] A. García-Segura, A. Fernández-García, M.J. Ariza, F. Sutter, L. Valenzuela, Effects of reduced sulphur atmospheres on reflector materials for concentrating solar thermal applications, Corros. Sci. 133 (2018) 78-93. 
[32] F. Wiesinger, F. Sutter, A. Fernández-García, J. Reinhold, R. Pitz-Paal, Sand erosion on solar reflectors: accelerated simulation and comparison with field data, Sol. Energy Mater. Sol. Cells 145 (2016) 303-313.

[33] C. Sansom, A. Fernández-García, F. Sutter, H. Almond, P. King, L. Martínez-Arcos, Soiling and cleaning of polymer film solar reflectors, Energies 9 (2016) 1006.

[34] Devices and Services Portable Specular Reflectometer Model 15R-USB Operation and Maintenance Manual, Devices and Services (D\&S), Dallas, 2009.

[35] Perkin Elmer High Performance Lambda Spectrophotometers Hardware Guide, Perkin Elmer, United Kingdom, 2007.

[36] ISO 9050, Glass in Building, Determination of Light Transmittance, Solar Direct Transmittance, Total Solar Energy Transmittance, Ultraviolet Transmittance and Related Glazing Factors, International Organization for Standardization (ISO), Geneva, 2003.

[37] ASTM standard G173-03, Terrestrial Reference Spectra for Photovoltaic Performance Evaluation, American Society for Testing and Materials (ASTM), West Conshohocken, 2003.

[38] Zeiss 3D light microscope model Axio CSM 700 Operating Manual, Carl Zeiss MicroImaging GmbH., Jena, 2010.

[39] A. Fernández-García, F. Sutter, L. Martínez-Arcos, C. Sansom, F. Wolfertstetter, C. Delord, Equipment and methods for measuring reflectance of concentrating solar reflector materials, Sol. Energy Mater. Sol. Cells 167 (2017) 28-52.

[40] A. Fernández-García, L. Martínez-Arcos, F. Sutter, J. Wette, F. Sallaberry, R. Erice, et al., Accelerated Aging Test of Solar Reflectors according to the New AENOR Standard - Results of a Round Robin Test. In: SolarPACES 2017, Concentrating Solar Power and Chemical Energy Systems, Santiago de Chile, 2017. 